\title{
¿Es consciente el alumnado de secundaria de la patogenicidad de los microorganismos y de la problemática sobre la resistencia a los antibióticos?
}

\author{
Beatriz Robredo iD \\ Área de Didáctica de las Ciencias Experimentales, Facultad de Ciencia y Tecnología, Universidad de La \\ Rioja, Logroño.España. beatriz.robredo@unirioja.es \\ Carmen Torres (iD \\ Área de Bioquimica y Biología Molecular, Facultad de Ciencia y Tecnología, Universidad de La Rioja, \\ Logroño.España.carmen.torres@unirioja.es
}

[Recibido: 29 septiembre 2020. Revisado: 9 noviembre 2020. Aceptado: 25 marzo 2021]

Resumen: La resistencia a los antibióticos es una importante amenaza mundial para la salud pública que puede reducirse, en parte, mediante una educación adecuada. Sin embargo, se desconocen los conocimientos actuales de los estudiantes en este tema por escasez de investigaciones. Con este fin se ha realizado una encuesta a 364 estudiantes de $3^{\circ}$ de Educación Secundaria Obligatoria de seis institutos. Los resultados obtenidos muestran percepciones erróneas sobre la patogenicidad de los microorganismos, desconocimiento del uso de antibióticos exclusivo para bacterias y de los fómites como mecanismo de transmisión de enfermedades infecciosas. El alumnado no es consciente de lo que implica la situación actual de escasez de antibióticos y el problema de su resistencia. Los resultados concretos más destacados pueden servir de ayuda al profesorado como implicaciones didácticas o propuestas de modificación del curriculum, hacia uno menos teórico y más centrado en casos prácticos, inculcando actitudes hacia un uso responsable de los antibióticos y su importancia en la prevención y tratamiento de enfermedades infecciosas.

Palabras clave: antibióticos, bacterias, Educación Secundaria, microorganismos, resistencia a antibióticos.

Are secondary school students aware of the pathogenicity of microorganisms and the problem of antibiotic resistance?

Abstract: Antibiotic resistance is a major global threat to public health that can be reduced at least partially through proper education. Currently, however, students' knowledge is unknown due scarce research on this topic. To this end, a survey has been carried out on 364 secondary school students in their $3^{\text {rd }}$ year from six high schools. The results obtained show erroneous perceptions about the pathogenicity of microorganisms, lack of knowledge about the exclusiveness of antibiotics for bacteria and about fomites as a mechanism of the transmission of infectious diseases. The surveyed students are not aware of the implication that represents the current situation of the lack of antibiotics and the problem of their resistance. The most outstanding concrete results can be helpful to teachers as didactic implications or proposals to modify the curriculum, towards a less theoretical one and focused more on practical cases, instilling attitudes towards a responsible use of antibiotics and their relevance for prevention and treatment of infectious diseases.

Keywords: antibiotics, antibiotic resistance, bacteria, microorganisms, Secondary School.

Para citar este artículo: Robredo B. y Torres C. (2021) ¿Es consciente el alumnado de secundaria de la patogenicidad de los microorganismos y de la problemática sobre la resistencia a los antibióticos? Revista Eureka sobre Enseñanza y Divulgación de las Ciencias 18(3), 3301. doi: 10.25267/Rev_Eureka_ensen_divulg_cienc.2021.v18.i3.3301

\section{Introducción}

Hoy, más que nunca nos damos cuenta de la necesidad de contar con un fármaco que pueda mitigar o eliminar la COVID-19 o la trascendencia de encontrar una vacuna adecuada. Actualmente es un virus el causante de la pandemia que nos azota, pero la siguiente causa 
puede ser una bacteria multi-resistente. La resistencia a los antibióticos es una importante amenaza mundial para la salud pública (Benito et al. 2014, Liebana et al. 2013, WHO 2014).

Anualmente, 700.000 personas mueren en el mundo por infecciones debidas a microorganismos resistentes a antibióticos; se estima que para 2050 se podrían alcanzar las 10 millones de muertes al año si no se toman medidas (O'Neill 2016). La falta de nuevos antibióticos amenaza los esfuerzos mundiales para contener las infecciones resistentes a los medicamentos. Esta escasez es debida a la disminución de la inversión privada y la falta de innovación en el desarrollo de nuevos antibióticos. Actualmente hay 60 productos en desarrollo que aportan pocos beneficios sobre los tratamientos existentes y muy pocos se dirigen a las bacterias resistentes más críticas, bacterias gramnegativas (WHO 2020). No obstante, hay profundos avances en el uso de nuevas tecnologías de predicción molecular con actividad antibacteriana de notable acción contra bacterias multirresistentes (Stokes et al. 2020; Silva et al. 2020).

Existen varias razones por las cuales ocurre la resistencia a los antibióticos, como el mal uso por parte de los consumidores, la incorrecta práctica clínica, farmacéutica, veterinaria, la falta de medidas de prevención como el saneamiento, el lavado de manos, la seguridad de los alimentos y el agua, y la vacunación (WHO 2015). El uso excesivo e indebido de antibióticos, la falta de higiene y los fallos en el control de infecciones que facilitan la resistencia pueden reducirse mediante una educación adecuada (Young, Berry, Verlander, Ridgway y McNulty 2019). Es fundamental para abordar este problema crear conciencia sobre la resistencia a los antimicrobianos y promover el cambio de comportamiento a través de programas de comunicación pública dirigidos a diferentes audiencias (salud humana, salud animal, práctica agrícola, consumidores). Igualmente, incluir el uso de agentes antimicrobianos y la resistencia en los planes de estudio escolares también promoverá una mejor comprensión y conciencia desde una edad temprana (WHO 2014).

Los niños y jóvenes son nuestra generación futura de usuarios o incluso de prescriptores de antibióticos, sin embargo, desconocemos sus conocimientos, percepciones y actitudes con relación al uso de antimicrobianos. Excepto algún trabajo con estudiantes universitarios de China (Huang et al. 2013) y de EE. UU. (Haltiwanger, Hayden, Weber, Evans y Possner 2001), relacionados con el grado de satisfacción al recibir prescripción antibiótica, sabemos muy poco sobre la formación del alumnado en este ámbito. Hay alguna aportación bibliográfica puntual sobre el conocimiento de la gripe por parte del alumnado de secundaria (Romine, Barrow y Folk 2013) o sobre el VIH (Keselman, Kaufman y Patel 2004), donde los jóvenes relacionan erróneamente los antibióticos con el tratamiento de estas enfermedades víricas. Por tanto, es de gran importancia saber los conocimientos, percepciones, actitudes y hábitos de nuestros jóvenes en relación con el uso de los antimicrobianos.

Dejando a un lado los antibióticos y centrándonos únicamente en los microorganismos, tenemos alguna evidencia de investigaciones sobre los conocimientos de los estudiantes, destacando que son muy inferiores a las realizadas en otras áreas de ciencias (Byrne 2011), especialmente en el ámbito español (Ballesteros, Paños y Ruiz-Gallardo 2018). La mayoría de los trabajos sobre microorganismos se han llevado a cabo con alumnado mayor de 11 años (Hilge y Kattmann 2003, Simonneaux 2000), aunque también se ha mostrado cierto interés en las ideas de estudiantes más jóvenes (Byrne 2011; Díaz, López, García, Abuín, Nogueira y García 1996; Faccio et al. 2013; Mafra, Lima y Carvalho 2015), incluso de educación infantil (Ergazaki, Saltapida y Zogza 2010).

En cuanto a la enseñanza reglada en el ámbito español, en educación primaria no se hace mención explícita de los microorganismos, aunque se entiende que están contenidos en el bloque 3: Los seres vivos, dentro del apartado Otros reinos (BOE 2014, Real Decreto 126/2014). 
En educación secundaria (BOE 2015, Real Decreto 1105/2014), en la asignatura Biología y Geología de $1^{\circ}$ y $3^{\circ}$ de Educación Secundaria Obligatoria (ESO) se estudian los reinos de los seres vivos en el bloque 3: La biodiversidad en el planeta Tierra y las enfermedades infecciosas en el bloque 4: Las personas y la salud. Promoción de la salud; cabe destacar que en ninguna parte del curriculum se citan los antibióticos.

La biología escolar prepara para los estudios superiores en ciencias de la salud y convendría que incluyera también competencias para la vida y claves de inteligibilidad de los desafíos colectivos en numerosas áreas, incluyendo el desarrollo de la medicina, vacunas, antibióticos y otros productos de prevención o terapia (Perrenaud 2012).

Teniendo en cuenta la amenaza que supone la resistencia a los antibióticos para la salud mundial, así como la escasez de estudios similares llevados a cabo en el ámbito español, el principal objetivo de esta investigación es explorar los conocimientos y percepciones del alumnado sobre los microorganismos y su patogenicidad, el uso de antibióticos, la resistencia a los mismos, las actitudes hacia un uso responsable y la prevención de enfermedades infecciosas. El estudio se ha realizado en $3^{\circ}$ de ESO porque supone la etapa final formativa en el ámbito científico para una gran parte del alumnado, que a partir de este curso elegirá itinerarios de Humanidades, Ciencias Sociales o Arte y, por tanto, estos serán los contenidos últimos en esta temática que le permitirán desenvolverse en todos los ámbitos de su vida.

\section{Metodología}

\section{Cuestionario}

Para esta investigación se elaboró un cuestionario formado por seis apartados (Anexo 1), tras hacer una revisión de la literatura sobre ideas alternativas extendidas en el alumnado (Teodoro y Chambel 2013) y preguntas formuladas en otras investigaciones (Bandiera 2007; Huang et al. 2013), utilizando un lenguaje comprensible para los estudiantes de $3^{\circ}$ de ESO y siguiendo el consejo y revisión de expertos. Los especialistas que han participado son los siguientes: miembros del grupo de investigación "Resistencia a los antibióticos desde un enfoque OneHealth" de la Universidad de La Rioja, que lleva tres décadas investigando sobre esta problemática; profesorado de Didáctica de las Ciencias Experimentales y de educación secundaria, que han aportado su experiencia en educación.

Con el apartado 1 se pretende saber si el alumnado considera y tiene en cuenta a los microorganismos y, en concreto, a las bacterias dentro del conjunto de seres vivos, por lo que la primera pregunta que se formula es abierta y las dos siguientes concretan la información buscada. En el apartado 2 se pretende profundizar en el grado de conocimiento sobre los distintos tipos de microorganismos, incluyendo su reconocimiento visual. El apartado 3 consta de dos preguntas cerradas que pretenden detectar errores habituales sobre la localización de las bacterias, los cuales se consideran de gran trascendencia para entender la capacidad de contagio y el conocimiento del impacto de los microorganismos en los distintos sectores. Los apartados 4, 5 y 6 tratan la percepción sobre el uso de antibióticos, la resistencia a los mismos y los hábitos y actitudes hacia la prevención de enfermedades infecciosas. El último apartado indaga acerca de las fuentes previas de obtención de los conocimientos sobre microorganismos, como ayuda para contextualización de los grupos de trabajo.

Para validar el cuestionario se pidió la colaboración de alumnos y alumnas de "Máster Universitario en Profesorado de Educación Secundaria Obligatoria y Bachillerato", que cumplimentaron el formulario y lo probaron con estudiantes aleatorios de $3^{\circ}$ de ESO. A partir de estos resultados se realizaron las calibraciones pertinentes. 


\section{Ámbito de estudio y muestra}

Se distribuyó el cuestionario on line mediante la herramienta Formulario de Google a 364 estudiantes de 14-15 años, cursando $3^{\circ}$ de ESO en seis Institutos de Educación Secundaria (IES), localizados en la ciudad de Logroño durante los cursos académicos 2018-2019 y 20192020. Se seleccionó este curso porque, como ya se ha citado en el objetivo del trabajo, supone la etapa final formativa en ámbito científico para una gran parte del alumnado, que a partir de este curso elegirá itinerarios de Humanidades, Ciencias Sociales o Arte. Se buscó heterogeneidad en los estudiantes: pertenecientes a institutos concertados y públicos, a 25 clases diferentes con profesorado diverso, usando metodologías y libros de texto variados; lo cual se traduce en una heterogeneidad de conocimiento.

Con el fin de contextualizar estos grupos de trabajo se analizaron las respuestas del último apartado: "Fuentes de obtención de los conocimientos sobre microorganismos". La formación recibida sobre microorganismos tuvo un valor medio de 1,9 en Educación Primaria y 2,6 en Educación Secundaria, según una escala Likert de 0 a 4, destacando que ningún encuestado señala no haber recibido nunca información sobre microorganismos. Además de la enseñanza reglada, los estudiantes manifiestan haber recibido información sobre microorganismos en charlas informativas (245 alumnos/as), en medios de comunicación generalistas como televisión, radio o periódicos (233), redes sociales (133), museos y visitas (81) y revistas especializadas (64).

\section{Análisis de datos}

Para el análisis de las preguntas abiertas, se generaron categorías de forma inductiva a partir de las respuestas de los estudiantes y posteriormente se determinó el porcentaje con el que fue elegida cada una de ellas, de acuerdo con análisis desarrollados por otros autores (González 2009). Las categorías se realizaron por dos investigadores de manera independiente y se consensuaron posteriormente. Finalmente, todas las respuestas se revisaron con mayor precisión para confirmar la categoría en la que se incluyó cada respuesta.

En el caso de las preguntas cerradas, se determinaron los porcentajes con los que fueron elegidas cada una de las respuestas.

\section{Resultados y discusión}

La elaboración de un currículum efectivo y la implementación de estrategias de enseñanzaaprendizaje que mejoren la enseñanza de las ciencias exigen conocer las preconcepciones que tienen los alumnos en relación con un contenido. El verdadero aprendizaje significativo pasa por el descubrimiento de aquellas ideas iniciales que los alumnos tienen sobre un determinado concepto o fenómeno científico (Allen 2010). Conocer las similitudes y diferencias entre la ciencia del alumnado y el conocimiento científico ha de ser un elemento central en la enseñanza de las ciencias (Osborne y Freyberg 1985).

\section{Conocimientos generales sobre los seres vivos}

Las respuestas a la primera pregunta abierta del formulario ¿Cómo se clasifican los seres vivos? se estructuraron en siete categorías (A-G) (Figura 1). El 6,9\% del alumnado se encuentra en la categoría A que define los 5 reinos: moneras, protoctistas, fungi, metafitas y metazoos. Un $2,1 \%$ (categoría B) se olvida del reino monera o del reino protoctista. El 24,3\% (categoría C) clasifica los seres vivos en reinos, sin especificar cuáles son y el 7,3\% (categoría D) los divide en unicelulares y pluricelulares. Casi la mitad del alumnado da una respuesta errónea (categorías E, F), lo cual hace pensar que le cuesta recordar estos contenidos (impartidos en primaria y $1^{\circ}$ de ESO), aunque seguramente con una pregunta cerrada con opciones las 
respuestas hubiesen sido más acertadas. Las dificultades en recordar los distintos seres vivos hacen evidente la necesidad de cambiar la metodología hacia una más práctica. Quizá la creación de conocimiento científico, mediante la realización de prácticas de microbiología (López y Boronat 2018), microscopía (Boronat y López 2019), biodiversidad (Rodriguez 2017), biotecnología (Curia, D'Alessandro y Briand 2010) y proyectos de investigación sobre microorganismos (Del Barrio, Guiral, Pifarré, Font y Martí 2018), pueden ayudar a solventar estas dificultades de recuerdo.

\section{¿Cómo se clasifican los seres vivos?}

A. En 5 reinos: animal, vegetal, hongos, protoctistas y moneras

B. En 4 reinos: se dejan el reino protoctistas o moneras

C. Reinos; sin citar qué reinos son

D. Unicelulares y pluricelulares

E. Solo consideran animales

F. Respuestas erróneas

G. Respuestas en blanco
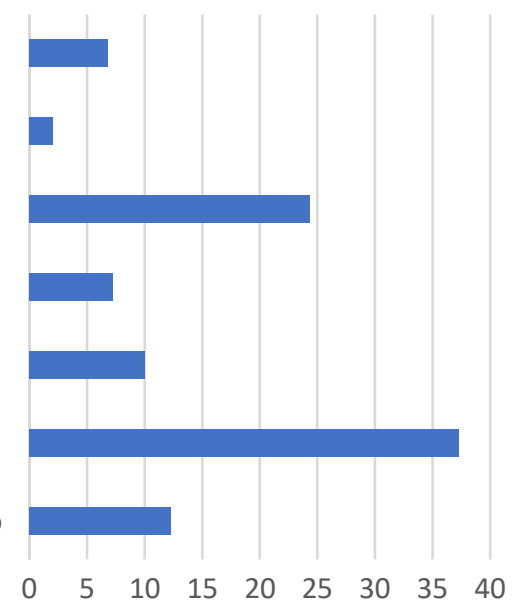

Figura 1. Categorización en torno a la pregunta ¿Cómo se clasifican los seres vivos?.

Una vez clasificados los seres vivos, se pretende ver la inclusión de las bacterias y los virus. El $83 \%$ del alumnado afirma que las bacterias son seres vivos y un $34 \%$ piensa que los virus también lo son (Figura 2). Esta es una de las concepciones alternativas más frecuentes, que incluso se ha detectado en maestros en formación (Marcos y Esteban 2017). Saber que los virus carecen de estructura celular y son parásitos intracelulares obligados es de gran trascendencia para poder comprender, a posteriori, que el mecanismo de ataque y destrucción de estas partículas infectivas es diferente al de las bacterias.

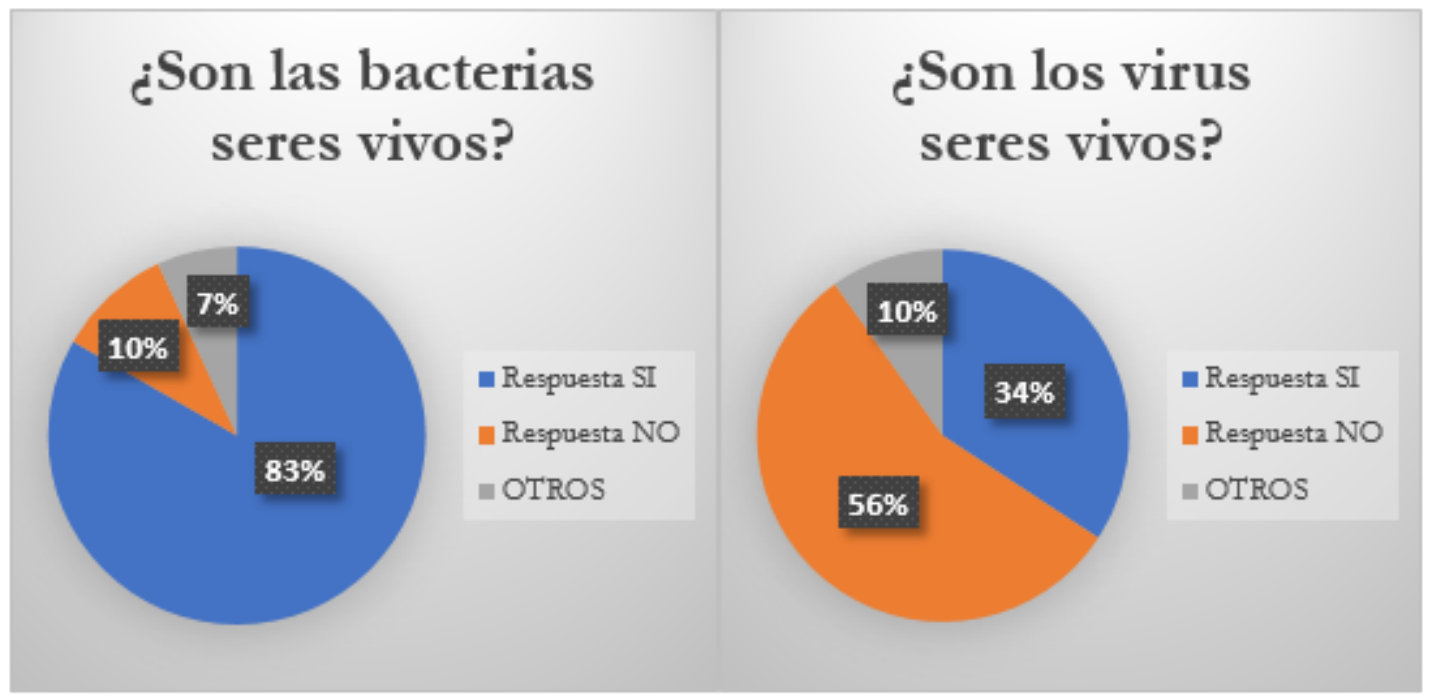

Figura 2. Porcentaje de respuestas a las preguntas: ¿Son las bacterias seres vivos? (izquierda); ¿Son los virus seres vivos? (derecha). 


\section{Conocimientos generales sobre microorganismos}

El 65,66\% del alumnado define correctamente a los microorganismos como organismos microscópicos, muy pequeños, unicelulares, que solo pueden ser observados con la ayuda del microscopio. Por tanto, algo que los alumnos parecen tener muy claro es el tamaño de los microorganismos, como también sucede en los trabajos de Byrne (2011) o Simonneaux (2000). Esta característica aparece en todos los libros de texto estudiados (Ballesteros et al. 2018). Pero aparte del tamaño, el alumnado de este estudio no aporta otras características, nombrando únicamente su ubicuidad y posibilidad de ser patógenos o beneficiosos. Ante la pregunta Indica alguna característica que conozcas de los microorganismos, solo 10 alumnos aportan nuevas ideas, seguramente por pereza a responder; las características nombradas son: algunos microorganismos son perjudiciales y otros no, pueden ser procariotas o eucariotas, autótrofos o heterótrofos, hábitat variable. Además, consideramos difícil que recuerden características de los microorganismos que, en general, ni siquiera han comprobado en un laboratorio de forma práctica.

En relación con la pregunta Indica el nombre de todos los microorganismos que conozcas, el 41,21\% no sabe, no contesta o cita nombres incorrectos. Prácticamente todo el alumnado que contesta a esta pregunta $(58,79 \%)$ nombra grupos genéricos: bacterias (152), virus (124), protozoos (94), hongos (84), algas (19) y levaduras (3). Solo 26 estudiantes, el 7,14\% del total, indican nombres concretos; los microorganismos nombrados son: virus de la gripe, del sida o VIH, herpes, papiloma virus, ébola, bacteriófagos, L. casei, estreptococos, estafilococos, amebas y paramecios. Los más citados están dentro del grupo de los virus y los menos, del grupo de las levaduras. En la bibliografía encontramos cómo las bacterias se confunden con hongos (Simonneaux 2000), las bacterias y los virus se perciben como idénticos (Byrne 2011; Jones y Rua 2006; Simonneaux 2000) o incluso las bacterias son la causa de los virus (Jones y Rua 2006).

En cuanto al reconocimiento visual de microorganismos, es de un $41,76 \%$ para las bacterias con morfología alargada, tipo bacilar, y 19,51\% para las bacterias con morfología redonda, tipo cocoide. Igualmente, un 39,29\% reconocen a los virus con envoltura esférica (como el virus de la gripe) y un 17,58\% a los virus de estructura compleja como el bacteriófago T4 (cuerpo icosaédrico, unido a una cola helicoidal con una base hexagonal con fibras caudales proteicas), a pesar de que se ha visto en otros trabajos que cuando los encuestados tienen que dibujar un virus la mayoría optan por un bacteriófago, que aunque no representa a la mayoría de los virus, sí que es una imagen que aparece mucho en los libros de texto (Jones y Rua 2006). El organismo B es identificado como levadura por un $8,79 \%$ de los estudiantes, y como hongo por un $11,54 \%$. Esta pregunta es tachada por algunos alumnos/as como la más difícil del cuestionario, a pesar de que, a partir de tercero de primaria, según se ha comprobado al analizar las diferentes editoriales, los libros de texto de Ciencias Naturales incluyen imágenes de microorganismos (Ballesteros et al. 2018). En este mismo trabajo, donde los estudiantes de primaria hacen dibujos de microorganismos, se observa que son pocos los dibujos analizados que pueden identificarse con alguna forma microbiana de las que se trabajan en estos cursos y los que sí lo hacen corresponden principalmente a bacterias, que es una de las tipologías más representadas tanto en los libros analizados y otros de referencia, como en pósteres de hospitales o consultas médicas (Byrne 2011). Por tanto, parece ser que no se le da la suficiente importancia al estudio de fotos o imágenes, a pesar de que es una parte inherente del proceso de enseñanza-aprendizaje de las ciencias (Galera y Ruiz-Gallardo 2016).

A partir de las fotos de la pregunta anterior el alumnado debe contestar si son perjudiciales o no para los seres vivos. Un 58,79\% reconocen a los virus como perjudiciales, un $63,19 \%$ a las bacterias (bacilos y cocos, con un 31,59\% y $27,47 \%$ respectivamente) y solo un $18,41 \%$ opina que las levaduras son perjudiciales. En cuanto a la justificación a la respuesta, ante los 
organismos A, B y D piensan que pueden ser buenos o malos, mientras que $\mathrm{C}$ y $\mathrm{E}$ siempre son perjudiciales; algunos estudiantes expresan que los organismos $\mathrm{C}$ y $\mathrm{E}$ tienen forma de malos (Tabla 1). Curiosamente, aunque no reconozcan visualmente a los microorganismos, sí aciertan en saber cuáles son perjudiciales para los seres vivos. Parece ser que la forma les sugiere cierta patogenicidad.

Tabla 1. Reconocimiento visual de los microorganismos y criterio de percepción de su perjuicio para los seres vivos.

\begin{tabular}{|l|l|c|c|c|c|}
\hline \multirow{2}{*}{ Imagen } & \multirow{2}{*}{ Microorganismo } & \multirow{2}{*}{$\begin{array}{c}\text { Reconocimiento } \\
\text { visual (porcentaje) }\end{array}$} & \multicolumn{3}{|c|}{ Son perjudiciales para los seres vivos } \\
\cline { 4 - 6 } & & & $\mathbf{S i}$ & $\mathbf{N o}$ & No lo sé \\
\hline Organismo A & Bacteria, bacilo & 41,76 & 31,59 & 39,01 & 29,40 \\
\hline Organismo B & Levadura, hongo & 20,33 & 18,41 & 40,66 & 40,93 \\
\hline Organismo C & Virus de la gripe & 39,29 & 58,79 & 14,01 & 27,20 \\
\hline Organismo D & Bacteria, coco & 19,51 & 27,47 & 34,34 & 38,19 \\
\hline Organismo E & Bacteriófago T4 & 17,58 & 63,19 & 9,34 & 27,47 \\
\hline
\end{tabular}

\section{Percepción sobre la patogenicidad de los microorganismos}

La mitad del alumnado (47\%) piensa que todas las enfermedades están producidas por microorganismos. Sin embargo, la mayoría $(76,5 \%)$ reconoce que todos los virus son perjudiciales para los seres vivos, pero no todas las bacterias $(23,5 \%)$ o los microorganismos en general (14,3\%) (Figura 3). Las bacterias se perciben como menos peligrosas que los virus o incluso se cree que las bacterias no son muy dañinas y solo es probable que se conviertan en peligrosas cuando están en mucha cantidad (Simonneaux 2000). En algunos estudios la virulencia y la rápida proliferación se han equiparado con el tamaño (Byrne 2011; Jones y Rua 2006). Los resultados de esta investigación no suponen una visión tan limitada y negativa de los microorganismos como la observada en trabajos anteriores con alumnos de educación primaria (Byrne 2011; Byrne y Grace 2010; Gillen y Williams 1993; Harms 2002; Jones y Rua 2006; Simonneaux 2000), considerándolos, básicamente, agentes perjudiciales, causantes de enfermedades en los seres humanos.

La mayoría del alumnado encuestado sabe que en la fabricación del pan $(69,4 \%)$, en la elaboración del yogur $(71,4 \%)$ o en el proceso de digestión $(75,5 \%)$ intervienen los microorganismos (Figura 3). Aunque, en general, en la explicación de estos fenómenos, se han detallado ideas alternativas en otras investigaciones (Díaz et al. 1996, Byrne 2011).

También reconoce que hay bacterias en el aire, en la cocina o en la nevera, aunque el $70 \%$ piensa erróneamente que la refrigeración elimina las bacterias (Figura 3). La ubicuidad de los microorganismos es una de sus características mencionadas y es generalmente conocida por los estudiantes (Byrne 2011; Teodoro y Chambel 2013), aunque en algunas investigaciones se ha visto la falta de reconocimiento de los microorganismos en una mesa limpia, el aire del campo o las profundidades marinas (Marcos y Esteban 2017). A veces, el cuerpo humano es la opción más elegida por los estudiantes (Ballesteros et al. 2018), concretamente las manos, asociándose así su presencia con la falta de higiene (Karandon y Sahin 2010), objetos que manipula el hombre (Jones y Rua 2006) u otras localizaciones (Faccio et al. 2013). 


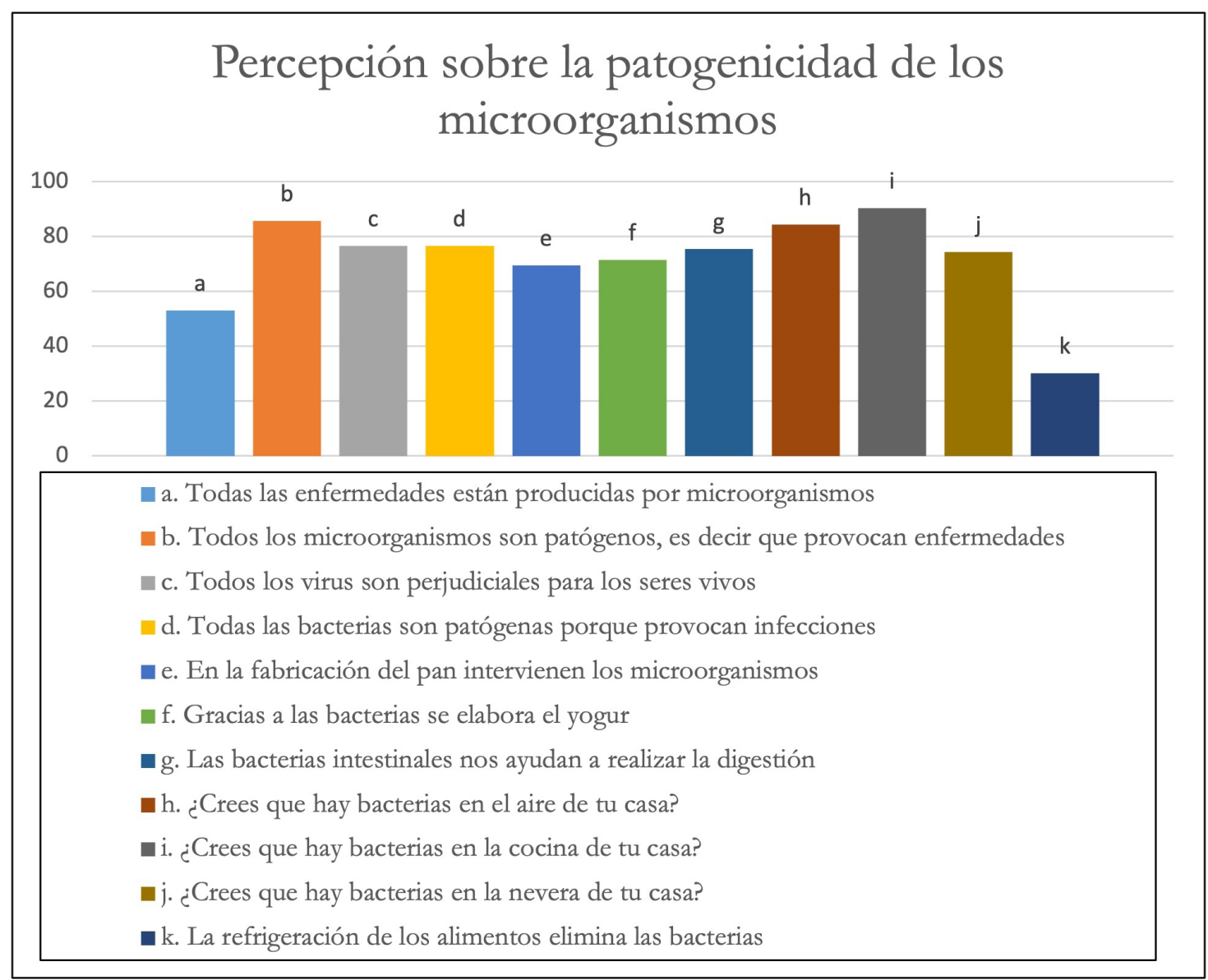

Figura 3. Porcentajes de acierto relativos a las preguntas de percepción sobre la patogenicidad de los microorganismos

En cuanto a los sectores sobre los que pueden tener impacto los microorganismos, el 88,4\% del alumnado señala la industria alimentaria; $82,4 \%$ y $83,2 \%$, la agricultura y ganadería, respectivamente; $74,2 \%$, la medicina; $67,3 \%$, la farmacia y $46,4 \%$, marcan todos los sectores. Por tanto, el alumnado no relaciona todos los sectores sobre los que pueden tener impacto los microorganismos; algunos piensan que solo es la industria alimentaria, otros la agricultura y ganadería y en menor medida la medicina o la farmacia. Parece ser que no se conocen las aplicaciones tan relevantes que los microorganismos tienen en ámbitos como la medicina, ciclos químicos o protección ambiental, conclusión a la que también llegan Byrne y Grace (2010).

\section{Percepción sobre el uso de antibióticos}

Desgraciadamente, más de la mitad del alumnado no sabe que no se deben utilizar los antibióticos que hayan sobrado de otros tratamientos y que solo se deben usar antibióticos ante una infección bacteriana (Tabla 2, destacado en gris). Se ha descrito en la bibliografía un desconocimiento del alumnado de secundaria en relación con la limitación del uso de antibióticos a las bacterias (Romine et al. 2013).

Todavía casi un 30\% del alumnado cree que los antibióticos son útiles contra las enfermedades causadas por virus y contra la gripe, percepción también puesta de manifiesto en otras investigaciones (Romine et al. 2013). Para cambiar estas ideas alternativas tan forjadas, en general, en nuestra sociedad es recomendable trabajarlas minuciosamente. Puede ser interesante realizar alguna práctica concreta de laboratorio, como, por ejemplo, probar directamente la actividad de la penicilina sobre microorganismos, donde se ve que solo actúa frente a bacterias y además su eficacia se centra en las bacterias grampositivas, con lo cual se evidencia que no todos los antibióticos sirven para todas las bacterias (López y Boronat 2018). 
Tabla 2. Respuestas a la pregunta ¿Cuándo se deben tomar antibióticos? en número de estudiantes y porcentaje de aciertos

\begin{tabular}{|l|c|c|}
\hline \multicolumn{1}{|c|}{$\begin{array}{c}\text { ¿Cuándo se deben tomar antibióticos? } \\
\text { Señas respuestas que consideres correctas: }\end{array}$} & $\begin{array}{c}\mathbf{N}^{\mathbf{o}} \text { de estudiantes que } \\
\text { señalan esta afirmación } \\
\text { como correcta }\end{array}$ & $\begin{array}{c}\text { Porcentaje de } \\
\text { aciertos }\end{array}$ \\
\hline Nunca porque tienen muchos efectos secundarios & 13 & 96,43 \\
\hline Solo cuando los receta el médico & 324 & 89,01 \\
\hline Cuando se tiene fiebre; pero en cuanto remite hay que dejar de tomarlos & 125 & 65,66 \\
\hline Cuando tenemos gripe & 108 & 70,33 \\
\hline Cuando tenemos cualquier infección causada por virus & 106 & 70,88 \\
\hline Cuando tenemos una infección bacteriana & 160 & 43,96 \\
\hline Los antibióticos solamente se emplean para curar enfermedades & 76 & 79,12 \\
\hline $\begin{array}{l}\text { No se deben usar los antibióticos que hayan sobrado de otros } \\
\text { tratamientos }\end{array}$ & 161 & 44,23 \\
\hline
\end{tabular}

En este apartado además se formulan algunas preguntas abiertas donde se especifican más las enfermedades y los antibióticos utilizados para su tratamiento. El 78,3\% del alumnado afirma haber tenido alguna enfermedad y haber tomado antibióticos para curarse. Las enfermedades para las que tomaron antibiótico fueron las siguientes: gripe, anginas, catarro, otitis, dolor de cabeza e infecciones entre las que citan apendicitis, sinusitis, amigdalitis, laringitis, gastroenteritis, bronquitis y conjuntivitis (Figura 4). Por tanto, algunos estudiantes siguen citando erróneamente la gripe, el catarro o incluso el dolor de cabeza. Ya se ha descrito anteriormente el desconocimiento del alumnado sobre la causa del catarro (Haltiwanger et al. 2001), la limitación del uso de antibióticos a las enfermedades bacterianas (Romine et al. 2013), la idea de cómo los antibióticos se asocian a enfermedades graves o incluso de que los antibióticos pueden mantenernos a salvo del VIH (Keselman et al. 2004).

\section{Enfermedades para las que el alumnado afirma haber tomado antibióticos}

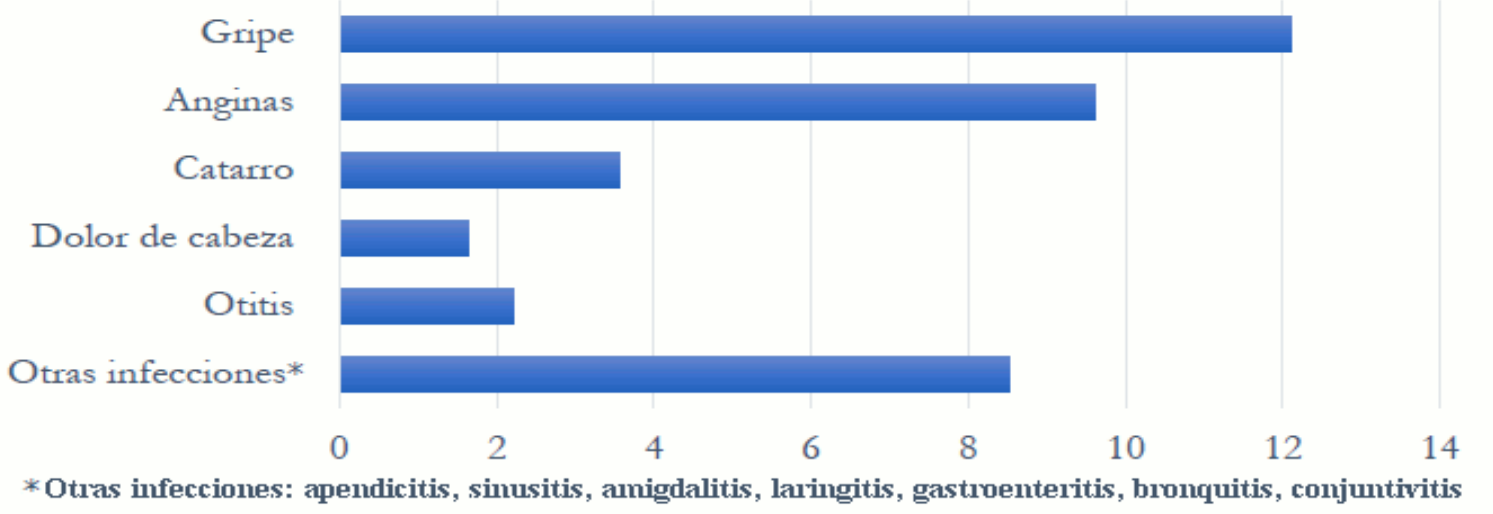

Figura 4. Porcentaje de estudiantes que afirman haber tomado antibióticos para el tratamiento de ciertas enfermedades.

Los antibióticos que tomaron para tratar estas enfermedades fueron: ibuprofeno (33 alumnos/as), dalsy (27), paracetamol (20), amoxicilina (17), augmentine (3); corticoides, espidifen, bisolgrip, flutox, frenadol, aspirina, apiretal y toseína (1 o 2 alumnos/as). Por tanto, el único antibiótico correcto, citado por un 5,5\% del alumnado, es la amoxicilina y $0,82 \%$ nombran el "augmentine". En definitiva, el desconocimiento de los medicamentos que son antibióticos y la relación con las enfermedades para las que se utilizan es enorme. Incluso sabiendo que los antibióticos no son adecuados para las infecciones víricas, los estudiantes piensan que necesitan antibióticos cuando contraen una infección viral (Haltiwanger et al. 2001). 


\section{Resistencia a los antibióticos}

$\mathrm{Al}$ realizar el formulario pensamos que podría ser lógica para los estudiantes la errónea idea de que son los seres humanos los que se hacen resistentes a los antibióticos en vez de las bacterias. Sin embargo, en este estudio, solo el 30\% del alumnado afirma que las personas somos resistentes a los antibióticos si abusamos de su uso (Figura 5).

Aunque la mayoría del alumnado cree correctamente que las bacterias resistentes a los antibióticos pueden transmitirse al ser humano por contacto con animales vivos, alimentos o agua $(68 \%)$ y por contacto con una persona infectada $(63 \%)$, menos de la mitad, piensan que pueden transmitirse por contacto con un utensilio que haya tocado una persona infectada (Figura 5). Curiosamente se ha descrito cómo alumnado y profesorado ven a los microorganismos casi siempre relacionados con el hombre y los objetos que manipula, en vez de visualizarlos como organismos libres e independientes (Jones y Rua 2006). Aun así, según los resultados obtenidos, nuestros encuestados y encuestadas no perciben la transmisión por contacto con un utensilio que haya tocado una persona infectada.

Piensan que es necesario cumplir con el calendario de vacunación $(86 \%)$ y consideran falsa la afirmación de que las vacunas aumentan la resistencia a los antibióticos (71\%). Las vacunas entrenan al sistema inmunitario para que reconozca y desarrolle una defensa inmune y efectiva contra el patógeno, por tanto, ayudan a reducir el riesgo de infección, evitando la enfermedad y el posible tratamiento antibiótico para su curación (Figura 5). Aunque en alguna ocasión se ha descrito cómo el alumnado piensa que la vacuna contra la gripe nos protege de la gripe por suministrarnos antibióticos (Romine et al. 2013).

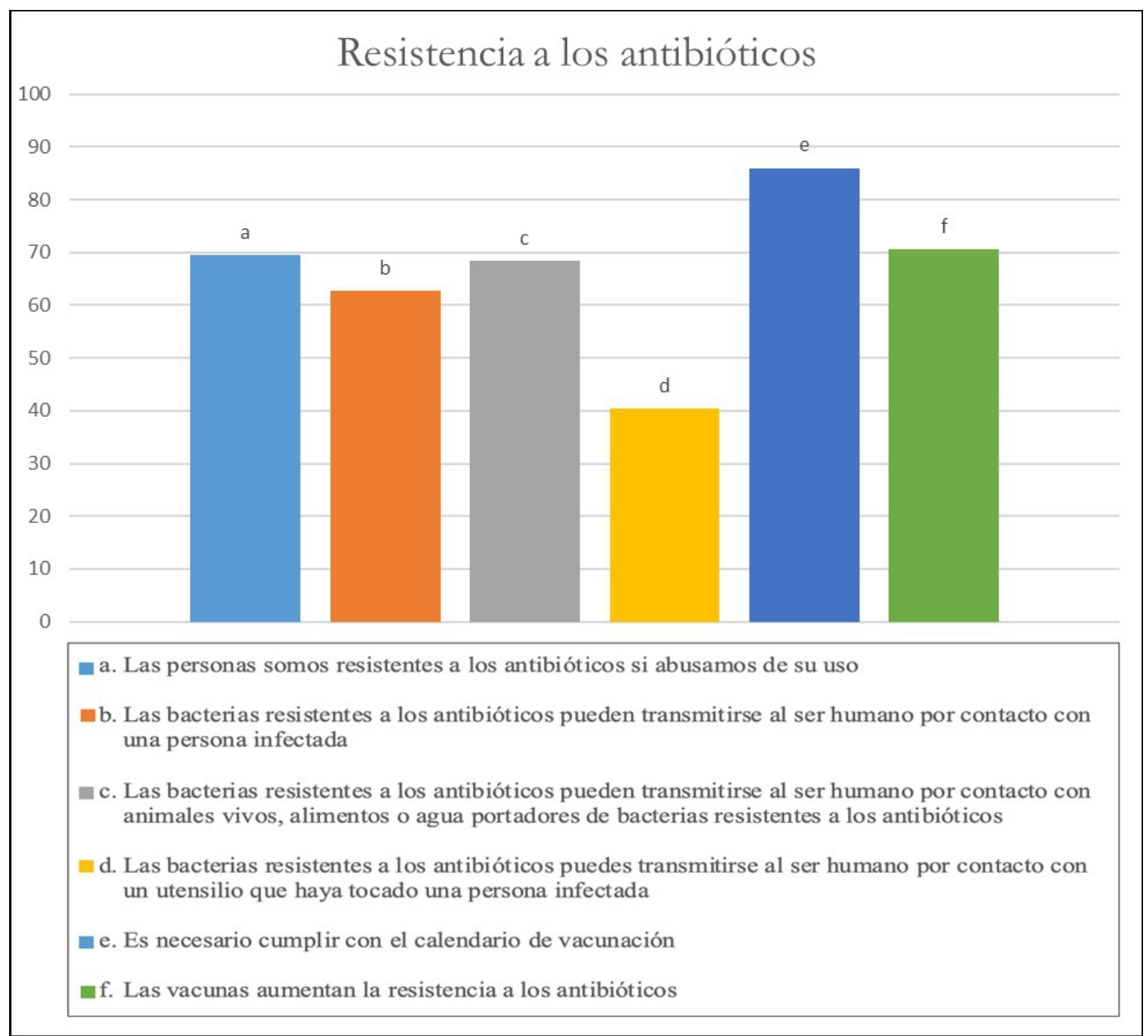

Figura 5. Porcentaje de aciertos relativos a las preguntas sobre la resistencia a los antibióticos. 
Pocos alumnos son conscientes de la gravedad existente cuando se contrae una infección bacteriana y esas bacterias son resistentes a los antibióticos. Ante la pregunta ¿Qué puede ocurrir si contraes una infección bacteriana y esas bacterias son resistentes a los antibióticos? se percibe un cierto positivismo en las respuestas del alumnado. Solamente el $12,64 \%$ ve la gravedad existente cuando se contrae una infección bacteriana y esas bacterias son resistentes a los antibióticos; el $7,14 \%$ habla de muerte y el 5,49\% piensa que no hay curación posible. Los demás estudiantes son muy optimistas pensando que hay otros métodos u otros antibióticos para tratar esta infección causada por bacterias resistentes. Por tanto, desconocen la situación actual de carencia de antibióticos para contener muchas de las infecciones por bacterias multirresistentes (WHO 2020).

El 28,85\% está de acuerdo con la siguiente afirmación: La resistencia a los antibióticos es una situación descontrolada y yo no puedo hacer nada para evitarla. El 67,86\% piensa que puede ayudar a detener la resistencia a los antibióticos mediante la vacunación (9 alumnos/as), acudiendo al médico o profesional ante una enfermedad (16 alumnos/as), no abusando del uso de antibióticos y tomándolos solo cuando sea necesario (50 alumnos/as). Algunos mencionan el empleo de los antibióticos de forma más controlada, la concienciación social, la investigación, crear antibióticos más fuertes u otros remedios, como solución a la resistencia a los antibióticos.

\section{Hábitos y actitudes hacia la prevención de enfermedades infecciosas}

Es alarmante el dato de que el 43,41\% del alumnado dice que cuando tiene gripe toma antibióticos rápidamente para curarse e intentar no contagiar a otras personas. Aunque la mayoría $(75,27 \%)$ piensa que solo se deben tomar antibióticos cuando los receta el médico, algunos $(12,36 \%)$ opinan que se pueden utilizar sin prescripción médica: si te encuentras mal, tienes conocimiento sobre la enfermedad, ya lo has tomado en otras ocasiones o tienes fiebre. Ante este fenómeno y a favor de un uso responsable de los antibióticos, países como China han iniciado la realización de programas educativos para niños en edad escolar y sus cuidadores (Zhang et al. 2018).

Un $73,9 \%$ dice lavarse las manos antes de comer para eliminar los microorganismos. Resultan muy prácticos para el aprendizaje los experimentos relacionados con el crecimiento de microorganismos en placa antes y después del lavado de manos (Faccio et al. 2013; López 2009). Las técnicas de lavado de manos constituyen un método básico de prevención de enfermedades infecciosas, que deberían enseñarse de forma práctica en los centros educativos a todos los niveles. Por fin en el curso 2020-2021 y desgraciadamente por la presión ante la COVID-19, la higiene de manos se está llevando a cabo en los centros educativos españoles (Gobierno de España 2021) y Universidades (Gobierno de España 2020).

\section{Aportaciones al profesorado}

Partiendo de estos resultados concretos más destacados, se pueden hacer aportaciones interesantes y útiles para el profesorado a través de dos vías: por un lado, implicaciones didácticas y, por otro, relacionadas con propuestas de modificación del currículum.

Las implicaciones didácticas derivadas de estos resultados nos dirigen al empleo de actividades prácticas en relación con los antimicrobianos, como algunas que ya se empiezan a realizar en nuestro país desde las Universidades, a partir de iniciativas internacionales como Small World Initiative (SWI) y Tiny Earth (Valderrama et al. 2018). Se recomienda trabajar también con juegos, redes sociales y programas educativos digitales como e-Bug. Este programa, dirigido por la Unidad de Atención Primaria de Public Health England, que involucra a un consorcio de 28 países, educa a niños y jóvenes sobre higiene, infección, vacunas y resistencia a los antibióticos (www.e-bug.eu) (McNulty et al., 2011). E-Bug ha sido evaluado y mejorado en 
varias ocasiones (Hawking, Lecky, Verlander y McNulty 2013; Lecky, Hawking, Verlander y McNulty, 2014; Hale, Young, Grand y McNulty 2017; Young et al. 2017; Eley, Young, Hoekstra y McNulty 2018).

En cuanto a la modificación del curriculum de secundaria, se propone incluir los antibióticos, la problemática de su resistencia, así como actitudes a tener en cuenta en relación con las enfermedades infecciosas y su tratamiento. Algunos libros de texto consultados de $3^{\circ}$ de ESO en el tema Salud y enfermedad ya incluyen los antibióticos, la problemática de la resistencia e indicaciones relativas a su uso (editoriales McGrawHill, Vicens Vives).

Hoy más que nunca, en este estado de pandemia, se necesita de una educación unidireccional, global, adecuada y práctica que llegue a todo el alumnado, tanto por su propia salud como por la de la sociedad. Tanto los conocimientos acertados encontrados, como los errores generalizados y que son, en definitiva, los obstáculos que han de superarse para una adecuada enseñanza pueden servir como punto de partida a las personas y entidades implicadas en la organización y secuenciación de contenidos de ciencias. Sobre esta base, podría abordarse, con más facilidad, el modo de reducir la distancia entre estos conocimientos y los científicamente aceptados, al tiempo que proponer actividades, recursos o representaciones más ajustadas a las necesidades reales. Esta investigación puede ayudar al nuevo Plan Nacional Frente a la Resistencia a los Antibióticos (PRAN) 2019-2021 que contempla la inclusión de la formación en materia de resistencia a antibióticos en educación infantil, primaria, secundaria y bachillerato.

Cabe recordar que el sistema educativo es responsable de promover una enseñanza que consiga que los alumnos/as adquieran un conocimiento científico objetivo, que les permita desenvolverse adecuadamente y con autonomía en todos los ámbitos de su vida (Ballesteros et al. 2018). Un currículum adaptado a las características de la sociedad actual debe incluir el estudio de los microorganismos (Byrne 2011), su relación con las enfermedades infecciosas y la co-responsabilidad en su tratamiento.

\section{Conclusiones}

Para el correcto uso de los antibióticos se debe comenzar por una educación adecuada. Este estudio explora los conocimientos y percepciones del alumnado sobre los microorganismos y su patogenicidad, el uso de antibióticos, la resistencia a los mismos, las actitudes hacia un uso responsable y la prevención de enfermedades infecciosas.

En concordancia con el contenido del currículo educativo español, el alumnado encuestado reconoce las bacterias como seres vivos y define correctamente los microorganismos. Sin embargo, se aprecia un escaso reconocimiento visual de los mismos.

$\mathrm{Si}$ nos adentramos en percepciones sobre la patogenicidad de los microorganismos encontramos errores importantes, destacando la idea de que todas las enfermedades están producidas por microorganismos o de que la refrigeración elimina las bacterias.

En lo que respecta a la percepción sobre el uso de antibióticos, el alumnado encuestado desconoce que los antibióticos son exclusivos para eliminar bacterias y, además, piensa que son útiles contra enfermedades causadas por virus.

Relativo a la resistencia a los antibióticos se pueden extraer tres conclusiones interesantes, en relación con las preguntas formuladas. La primera, en relación con la vehiculización de las bacterias resistentes a antibióticos, donde se observa que el alumnado es consciente de la posible transmisión de microorganismos entre personas, animales, alimentos o agua, pero más de la mitad no ve los fómites como objetos de contagio, por lo que se propone incidir más en 
los mecanismos de transmisión. En segundo lugar, los estudiantes encuestados no son conscientes de la situación actual de escasez de antibióticos para contener las infecciones por bacterias multirresistentes. $\mathrm{Y}$, en tercer lugar, es preciso difundir la idea de que todos podemos contribuir a evitar la resistencia a antibióticos ya que todavía hay estudiantes que creen que la situación es descontrolada y no pueden contribuir de ninguna manera para evitarla.

Casi la mitad del alumnado afirma tomar antibióticos cuando tiene gripe, aunque probado su desconocimiento de los medicamentos que son antibióticos es probable que no sean realmente antibióticos. Además, muy pocos dicen utilizarlos sin prescripción médica, lo cual garantiza su correcto uso. También se han encontrado actitudes positivas en los hábitos de higiene de manos.

Partiendo de estos resultados concretos más destacados, se pueden hacer aportaciones interesantes y útiles para el profesorado a través de dos vías: por un lado, implicaciones didácticas y, por otro, relacionadas con propuestas de modificación del currículum, hacia uno menos teórico y más centrado en casos prácticos, inculcando actitudes hacia un uso responsable de los antibióticos y su importancia en la prevención y tratamiento de enfermedades infecciosas.

\section{Agradecimientos}

Esta investigación ha sido financiada por un proyecto de divulgación convocado por la Unidad de Cultura Científica y de la Innovación (UCC+i) de la Universidad de La Rioja. Nuestra gratitud a los revisores de este trabajo que, con sus observaciones, comentarios y sugerencias, han contribuido a su mejora y nos han hecho aprender.

\section{Referencias}

Allen, M. (2010) Misconceptions in Primary Science. Berkshire: McGraw-Hill.

Ballesteros M. I., Paños E., Ruiz-Gallardo J. R. (2018) Los microorganismos en la educación primaria. Ideas de los alumnos de 8 a 11 años e influencia de los libros de texto. Enseñanza de las Ciencias, 36(1), 79-98. https://doi.org/10.5565/rev/ensciencias.2274

Bandiera M. (2007) Microorganisms: Everyday knowledge predates and contrasts with school knowledge. En R. Pintó y D. Couso (Eds.), Contributions from science education research (pp. 213-224). Dordrecht: Springer. https://doi.org/10.1007/978-1-4020-5032-9_16

Benito D., Lozano C., Rezusta A., Ferrer I., Vasquez M. A., Ceballos S., Zarazaga M., Revillo M.J., Torres C. (2014) Characterization of tetracycline and methicillin resistant Staphylococcus aureus strains in a Spanish hospital: is livestock-contact a risk factor in infections caused by MRSA CC398? Int J Med Microbiol. 304(8), 1226-32. https://doi: 10.1016/j.ijmm.2014.09.004

Byrne J. (2011) Models of Microorganisms: Children's knowledge and understanding of microorganisms from 7 to 14 years old. International Journal of Science Education, 33(14), 1927-1961. https://doi.org/10.1080/09500693.2010.536999

Byrne J., Grace M. (2010) Using a Concept Mapping Tool with a Photograph Association Technique (CoMPAT) to Elicit Children's Ideas about Microbial Activity. International Journal of Science Education, 32(4), 479-500. https://doi.org/10.1080/09500690802688071

BOE (2014) Real Decreto 126/2014, de 28 de febrero, por el que se establece el currículo básico de la Educación Primaria. https://www.boe.es/buscar/pdf/2014/BOE-A2014-2222-consolidado.pdf 
BOE (2015) Real Decreto 1105/2014, de 26 de diciembre, por el que se establece el currículo básico de la Educación Secundaria Obligatoria y del Bachillerato. https://www.boe.es/boe/dias/2015/01/03/pdfs/BOE-A-2015-37.pdf

Boronat, R., López, J. P. (2019). Una visión cercana de la microscopia en el laboratorio de Educación Secundaria. Región de Murcia: Consejería de Educación y Cultura.

Curia M., D'Alessandro O., Briand L. E. (2010) La Enseñanza de Conceptos en Biotecnología a través de un Experimento Sencillo y Económico. Formación Universitaria. 3(1), 27-30. https://doi.org/10.4067/S0718-50062010000100005

Del Barrio M., Guiral A., Pifarré M., Font N., Martí L. (2018) Crear conocimiento científico. Un proyecto de investigación sobre microorganismos. Alambique Didáctica de las Ciencias Experimentales, 91, 56-62.

Díaz R., López R., García A., Abuín G., Nogueira E., García J. A. (1996) ¿Son los alumnos capaces de atribuir a los microorganismos algunas transformaciones de los alimentos? Enseñanza de las Ciencias, 14(2), 143-153.

Ergazaki M., Saltapida K., Zogza V. (2010) From Young children's ideas about germs to ideas shaping a learning environment. Research in Science Education, 40(5), 699-715. https://doi.org/10.1007/s11165-009-9140-2

Eley C. V., Young V. L., Hoekstra B. A., McNulty, C. A. M. (2018) An evaluation of educators' views on the e-Bug resources in England. Journal of Biological Education, 52(2), 166-173. https://doi.org/10.1080/00219266.2017.1285808

Faccio E., Costa N., Losasso C., Cappa V., Mantovani C., Cibin V., Andrighetto I., Ricci A. (2013) What programs work to promote health for children? Exploring beliefs on microorganisms and on food safety control behavior in primary schools. Food control, 33(2), 320-329. https://doi.org/10.1016/j.foodcont.2013.03.005

Galera M., Ruiz-Gallardo J. R. (2016) Influencia de Concept Cartoons en la motivación y resultados académicos de los estudiantes. Revista Eureka sobre Enseñanza y Divulgación de las Ciencias, 12(3), 419-440. https://doi.org/10.25267/rev_eureka_ensen_divulg_cienc.2015.v12.i3.03

Gillen A. L., Williams R. P. (1993) Dinner date with a microbe. American Biology Teacher, 55(5), 268-274. https://doi.org/10.2307/4449658

Gobierno de España (2021) Ministerio de Educación y Formación Profesional y Ministerio de Sanidad. Medidas de prevención, higiene y promoción de la salud frente a COVID-19 para centros educativos en el curso 2020-2021. Versión 08/02/2021. Aprobado en Comisión de Salud Pública el 4-2-2021.

https://www.mscbs.gob.es/profesionales/saludPublica/ccayes/alertasActual/nCov/d ocumentos/COVID19_Medidas_centros_educativos_Curso_2020_2021.pdf

Gobierno de España (2020) Ministerio de Universidades. Recomendaciones del ministerio de universidades a la comunidad universitaria para adaptar el curso universitario 2020-2021 a una presencialidad adaptada y Medidas de actuación de las universidades ante un caso sospechoso o uno positivo de COVID-19. Versión actualizada de 31 de agosto de 2020. https://www.ciencia.gob.es/stfls/MICINN/Universidades/Ficheros/Recomendacione s_del_Ministerio_de_Universidades_para_adaptar_curso.pdf

González, L. (2009). "La sistematización y el análisis de los datos cualitativos" en R. Mejía y S. A. Sandoval (coords.), Tras las vetas de la investigación cualitativa, acercamientos desde 
las prácticas, Guadalajara: Instituto Tecnológico de Estudios Superiores de Occidente, pp. 155-174.

Hale A. R., Young V. L., Grand A. Y, McNulty C. A. (2017) Can gaming increase antibiotic awareness in children? A mixed-methods approach. JMIR Serious Games, 5(1): e5. https://doi.org/10.2196/games.6420

Haltiwanger K. A., Hayden G. F., Weber T., Evans B. A., Possner A. B. (2001) Antibioticseeking behavior in college students: what do they really expect? Journal of American College Health, 50(1), 9-13. https://doi.org/10.1080/07448480109595705

Hawking M. K., Lecky D. M., Verlander N. Q., McNulty, C. A. (2013) Fun on the farm: evaluation of a lesson to teach students about the spread of infection on school farm visits. PLoS One, 8(10): e75641. https://doi.org/10.1371/journal.pone.0075641

Harms, U. (2002) Biotechnology education in schools. Electronic Journal of Biotechnology, 5(3), 205-211. https://doi.org/10.2225/vol5-issue3-fulltext-i03

Hilge, C., Kattmann, U. (2003) The significance of microbes for biology teaching - A study of scientific students' conception. Actas de la $4^{\text {a }}$ Conferencia ESERA. Holanda: Noordwijkerhout.

Huang Y., Gu J., Zhang M., Ren Z., Yang W., Chen Y., Fu Y., Chen X., Cals J. W. L., Zhang, F. (2013) Knowledge, attitude and practice of antibiotics: a questionnaire study among 2500 Chinese students. BMC Medical Education, 13, 163.

Jones M. G., Rua, M. J. (2006) Conceptions of germs. Expert to novice understandings of microorganisms. Electronic Journal of Science Education, 10(3). Revista electrónica sin paginación.

Karandon H. D., Sahin, N. (2010) Primary school students' basic knowledge, opinions and risk perceptions about microorganisms. Procedia - Social and Behavioral Sciences, 2, 4398-4401. https://doi.org/10.1016/j.sbspro.2010.03.700

Keselman A., Kaufman D. R., Patel, V. L. (2004) "You can exercise your way out of HIV" and other stories: The role of biological knowledge in adolescents' evaluation of myths. Science Education, 88(4), 548-573. https://doi.org/10.1002/sce.10135

Lecky D. M., Hawking M. K., Verlander N. Q., McNulty, C. A. (2014) Using interactive family science shows to improve public knowledge on antibiotic resistance: does it work? PLoS One 9: e104556. https://doi.org/10.1371/journal.pone.0104556

Liebana E., Carattoli A., Coque T. M., Hasman H., Magiorakos A. P., Mevius D., Peixe L., Poirel L., Schuepbach-Regula G., Torneke K., Torren-Edo J., Torres C., Threlfall J. (2013) Public health risks of enterobacterial isolates producing extended-spectrum $\beta$ lactamases or AmpC $\beta$-lactamases in food and food-producing animals: an EU perspective of epidemiology, analytical methods, risk factors, and control options. Clinical Infectious Diseases. 56(7), 1030-7. https://doi: 10.1093/cid/cis1043

López, J. P. (2009) Microbiología básica en la educación secundaria obligatoria: el lavado de las manos. Revista Eureka sobre Enseñanza y Divulgación de las Ciencias. 6(2), 319-324. https://revistas.uca.es/index.php/eureka/article/view/3708

López, J. P., Boronat, R. (2018) Actividad de la penicilina sobre microorganismos. Alambique Didáctica de las Ciencias Experimentales. 92, 54-59.

López, J. P., Boronat, R. (2018). Prácticas de microbiología básica en el laboratorio de Educación Secundaria. Región de Murcia: Consejería de Educación, Juventud y Deportes. 
Mafra P., Lima N., Carvalho G. S. (2015) Experimental Activities in Primary School to Learn about Microbes in an Oral Health Education Context. Journal of Biological Education, 49(2), 190-203. https://doi.org/10.1080/00219266.2014.923485

Marcos J. M., Esteban, R. (2017) Concepciones alternativas sobre biología celular y microbiología de los maestros en formación: implicaciones de su presencia. Campo Abierto, 36 (2), 167-179.

McNulty C. A. M., Lecky D. M., Farrell D., Kostkova P., Adriaenssens N., Koprivová T., Holt J., Touboul P., Merakou K., Koncan R., Olczak-Pienkowska A., Avô A. B., Campos. J., Barbouni N., Beneš J., Rodriguez C., Cornaglia G., Davis C., De Corte S., De Quincey E., Dellamonica P., Gennimata D., Goossens H., Grzesiowski P., Jawaheer G., Kremastinou J., Lazareck L., Noer M., Nowakowska M., Weerasinghe D., Weinberg J., Fry C., Goossens,H., Fisher, I. (2011) Overview of e-Bug: an antibiotic and hygiene educational resource for schools. Journal of Antimicrobial Chemotheraphy, 66(5), 3-12. https://doi.org/10.1093/jac/dkr119

O’Neill J. (2016) Tackling drug-resistant infections globally: final report and recommendations. London: Review of AMR.

Osborne R., Freyberg P. (1985). Learning in Science. The Implications of Children's Science. Auckland: Heinemann Education.

Perrenaud P. (2012) Cuando la escuela pretende preparar para la vida. ¿Desarrollar competencias o enseñar otros saberes? Madrid: Graó.

PRAN 2019-2021 (Plan Nacional Frente a la Resistencia a Antibióticos 2019-2021) Ministerio de Sanidad Consumo y Bienestar Social. Obtenido de: http://resistenciaantibioticos.es/es/system/files/field/files/pran_2019-2021_0.pdf? file $=1 \&$ type $=$ node $\&$ id $=497 \&$ force $=0$

Rodriguez G. (2017) La biodiversidad de nuestra escuela: proyecto didáctico para trabajar la diversidad biológica. Ikastorratza. E-Revista de Didáctica. Revista electrónica sin paginación.

Romine W. L., Barrow L. H., Folk, W. R. (2013) Exploring secondary students' knowledge and misconceptions about influenza: development, validation, and implementation of a multiple-choice influenza knowledge scale. International Journal of Science Education, 1-28. https://doi.org/10.1080/09500693.2013.778439

Silva O. M., Torre M. D., Cao J., Alves E. S., Rodrigues L. V., Resende J. M., Liao L. M., Porto W. F., Fensterseifer I. C., Lu T. K., Franco O. L., Fuente-Nunez C. (2020) Repurposing a peptide toxin from wasp venom into antiifectives with dual antimicrobial and imnunomodulatory properties. PNAS, 117(43), 26936-26945. https://www.pnas.org/content/117/43/26936

Simonneaux L. (2000) A study of pupils' conceptions and reasoning in connection with 'microbes', as a contribution to research in biotechnology education. International Journal of Science Education, 6, 619-644. https://doi.org/10.1080/095006900289705.

Stokes J. M., Yang K., Swanson K., Jin W., Cubillos A., Donghia N., MacNair C. R., French S., Carfrae L. A., Bloom Z., Tran V. M., Chiappino A., Badran A., Andrews I., Chory E., Church G., Brown E. D., Jaakkola T. S., Barzilay R., Collins J (2020) A deep learning aproach to antibiotic discovery. Cell. 181(2), 475-483. https://doi:10.1016/j.cell.2020.04.001 
Teodoro A., Chambel L. (2013) The role of teachers in students' education for antibiotic use. En A. Mendez-Vilas (Ed.), Microbial pathogens and strategies for combating them: science, technology and educations (pp.1957-1968). Badajoz: Formatex Research Center.

Valderrama M. J., González-Zorn B., Calvo de Pablo P., Díez-Orejas R., Fernández-Acero T., Gil-Serna J., De Juan L., Martín H., Molina M., Navarro-García F., Patiño B., Pla J., Prieto D., Rodríguez C., Román E., Sanz-Santamaría A. B., De Silóniz M. I., Suárez M., Vázquez C., Cid V. J. (2018) Educating in antimicrobial resistance awareness: adaptation of the Small World Initiative program to service-learning. FEMS Microbiology Letters, 365, 161. https://doi.org/10.1093/femsle/fny161

WHO (World Health Organization) (2014) Antimicrobial Resistance: Global Report on Surveillance, 8-92. Geneva: World Health Organization.

https://www.who.int/drugresistance/documents/surveillancereport/en/

WHO (World Health Organization) (2015) Global action plan on antimicrobial resistance. Geneva: World Health Organization. https://www.who.int/publications/i/item/global-actionplan-on-antimicrobial-resistance

WHO (World Health Organization) (2020) Lack of new antibiotics threatens global efforts to contain drug-resistant infections. Geneva: World Health Organization. https://www.who.int/newsroom/detail/17-01-2020-lack-of-new-antibiotics-threatens-global-efforts-to-containdrug-resistant-infections

Young V. L., Cole A., Lecky D. M., Fettis D., Pritchard B., Verlander N. Q., Eley C. V., McNulty C. A. (2017) A mixed-method evaluation of peer- education workshops for school-aged children to teach about antibiotics, microbes and hygiene. Journal of Antimicrobial Chemotherapy, 72, 2119-2126. https://doi.org/10.1093/jac/dkx083

Young V. L., Berry M., Verlander N. Q., Ridgway A., McNulty, C. A. (2019) Using debate to educate young people in schools about antibiotic use and resistance: A before and after evaluation using a questionnaire survey. Journal of Infection Prevention, 20(6), 281-288. https://doi.org/10.1177/1757177419862039

Zhang Y., Kabba J., Chang J., Wenjing J., Zhu S., Yu J., Xu S., Fang Y. (2018) A school-based educational intervention for school-aged children and caregivers about rational use of antibiotics in urban areas of Shaanxi province: a study protocol for a randomized controlled research. International Journal of Environmental Research Public Health, 15, 1912. https://doi.org/10.3390/ijerph15091912 
Anexo 1. Cuestionario.

\section{CONOCIMIENTOS GENERALES SOBRE LOS SERES VIVOS}

1. ¿Cómo se clasifican los seres vivos?

2. ¿Son las bacterias seres vivos? Sí, No, No lo sé

3. ¿Son los virus seres vivos? Sí, No, No lo sé

\section{CONOCIMIENTOS GENERALES SOBRE MICROORGANISMOS}

1. Define microorganismo.

2. Indica alguna característica que conozcas de los microorganismos.

3. Indica el nombre de todos los microorganismos que conozcas.

4. Indica (si lo sabes) el nombre de los organismos que aparecen en las siguientes fotografías:
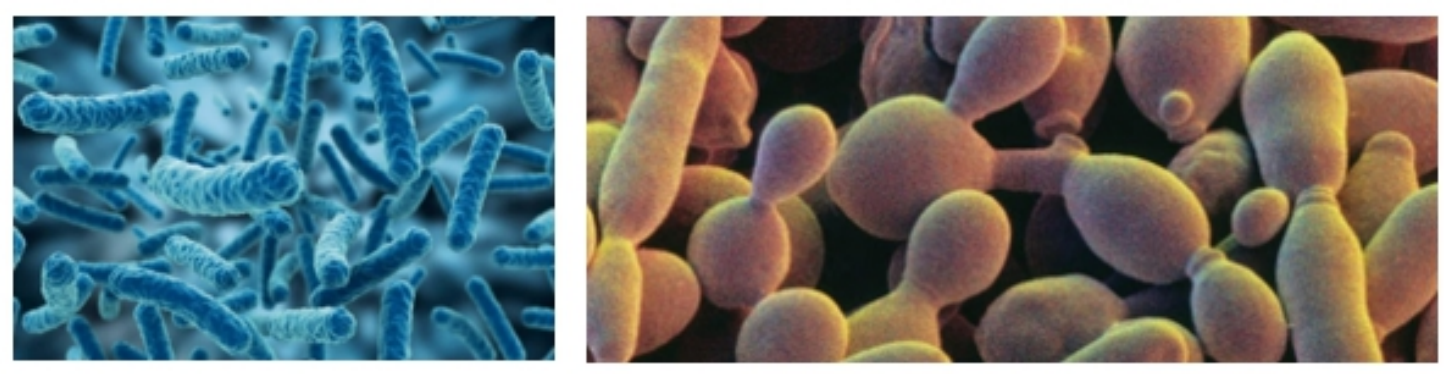

\section{Organismo $A$}

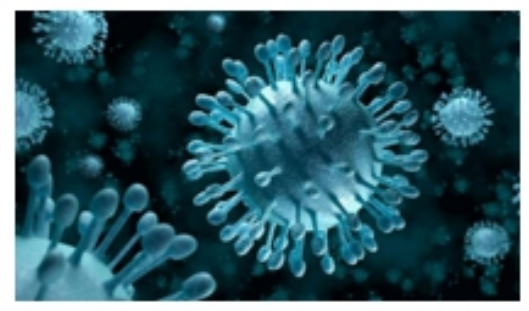

\section{Organismo $C$}

\section{Organismo $B$}

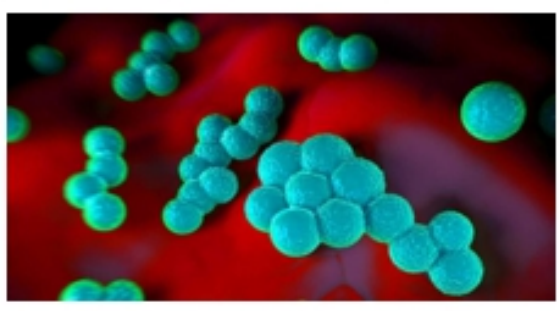

Organismo D

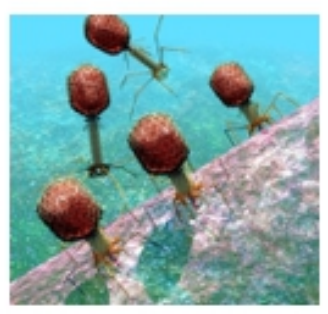

Organismo E

5. ¿Alguno de los organismos anteriores es perjudicial para los seres vivos? Si crees que sí, indica cuál o cuáles.

6. Justifica brevemente tus respuestas de la pregunta anterior indicando el criterio utilizado para considerar un organismo como perjudicial para los seres vivos.

\section{PERCEPCIÓN SOBRE LA PATOGENICIDAD DE LOS MICROORGANISMOS}

1. Contesta a las siguientes afirmaciones o preguntas: Sí, No, No lo sé

- Todas las enfermedades están producidas por microorganismos

- Todos los microorganismos son patógenos, es decir, provocan enfermedades

- Todos los virus son perjudiciales para los seres vivos

- Todas las bacterias son patógenas porque provocan infecciones

- En la fabricación del pan intervienen los microorganismos

- Gracias a las bacterias se elabora el yogur

- Las bacterias intestinales nos ayudan a realizar la digestión

- ¿Crees que hay bacterias en el aire de tu casa?

- ¿Crees que hay bacterias en la cocina de tu casa?

- ¿Crees que hay bacterias en la nevera de tu casa?

- La refrigeración de los alimentos elimina las bacterias

2. Señala los sectores sobre los que pueden tener impacto los microorganismos (marca todas las que consideres): Agricultura, Ganadería, Farmacia, Medicina, Industria alimentaria, Ninguna de las anteriores 
Anexo 1. Continuación.

PERCEPCIÓN SOBRE EL USO DE ANTIBIÓTICOS

1. ¿Cuándo se deben tomar antibióticos? Señala las respuestas que consideres correctas:

- Nunca, porque tienen muchos efectos secundarios

- Solo cuando los receta el médico

- Cuando se tiene fiebre; pero en cuanto remite hay que dejar de tomarlos

- Cuando tenemos gripe

- Cuando tenemos cualquier infección causada por virus

- Cuando tenemos una infección bacteriana

- Los antibióticos solamente se emplean para curar enfermedades

- No se deben usar los antibióticos que hayan sobrado de otros tratamientos

2. ¿Has tenido alguna enfermedad y tomaste antibióticos para curarte? Sí, No

3. En caso afirmativo, ¿recuerdas que enfermedad era?

4. ¿Recuerdas el nombre del antibiótico?

\section{RESISTENCIA A LOS ANTIBIÓTICOS}

1. Señala las respuestas que consideres correctas:

- Las personas somos resistentes a los antibióticos si abusamos de su uso

- Las bacterias resistentes a los antibióticos pueden transmitirse al ser humano por contacto con una persona infectada

- Las bacterias resistentes a los antibióticos pueden transmitirse al ser humano por contacto con animales vivos, alimentos o agua portadores de bacterias resistentes a los antibióticos

- Las bacterias resistentes a los antibióticos pueden transmitirse al ser humano por contacto con un utensilio que haya tocado una persona infectada

- Es necesario cumplir con el calendario de vacunación

- Las vacunas aumentan la resistencia a los antibióticos

2. ¿Qué puede ocurrir si contraes una infección bacteriana y esas bacterias son resistentes a los antibióticos?

3. La resistencia a los antibióticos es una situación descontrolada y yo no puedo hacer nada. Verdadero, Falso

4. En caso afirmativo ¿cómo puedes ayudar a detener la resistencia a los antibióticos?

\section{ACTITUDES HACIA LA PREVENCIÓN DE ENFERMEDADES INFECCIOSAS}

1. Cuando tengo gripe tomo antibióticos rápidamente para curarme e intentar no contagiar a otras personas. Sí, No, No lo sé

2. Me lavo las manos antes de comer para eliminar los microorganismos de las manos. Tal vez, Sí, No

3. Solo se deben tomar antibióticos cuando los receta el médico. Sí, No, Otro

\section{FUENTES DE OBTENCIÓN DE LOS CONOCIMIENTOS SOBRE MICROORGANISMOS}

1. La formación que recibí sobre diferentes aspectos relativos a microorganismos en Educación Primaria fue: Escala Likert de 0 (Ninguna) - 4 (Muy completa)

2. La formación que recibí sobre diferentes aspectos relativos a microorganismos en Educación Secundaria fue: Escala Likert de 0 (Ninguna) - 4 (Muy completa)

3. Señala las fuentes de las que hayas recibido información sobre microorganismos (Marca todas las que consideres):

- Medios de comunicación generalistas (televisión, radio, periódicos...)

- Redes sociales

- Revistas especializadas

- Charlas informativas

- Museos, visitas

- Nunca he recibido información sobre microorganismos 